\title{
Globalização, regionalismo e ordem internacional
}

\author{
VALÉRIE DE CAMPOS MELLO*
}

\section{Introdução}

O panorama internacional ao final da década de 90 apresenta um caráter paradoxal. Por um lado, predomina a sensação de estarmos vivendo uma profunda desordem econômica internacional. Acontecimentos tais como a atual crise financeira, afetando a Ásia e a Rússia, geram novas propostas para a regulamentação do sistema financeiro internacional, e encontros internacionais tais como o Fórum Econômico Mundial tornaram-se foros de debate sobre a chamada "ordem internacional" e as possibilidades de uma reforma que venha a disciplinar o pânico e o caos causados pela instabilidade dos fluxos econômicos internacionais. Sob tal ótica, o sistema mundial parece cada vez mais fragmentado e desregulado. Por outro lado, uma característica marcante do atual sistema internacional é a formação de blocos de integração regional. A integração regional se apresenta como uma tendência contrária à desregulação e à fragmentação: ela leva não só a um maior ordenamento e a uma institucionalização crescente das relações econômicas internacionais como também, em alguns casos, a um processo gradual de integração e cooperação política.

O exemplo mais claro de tal tendência é a União Européia, o processo de integração regional mais avançado que existe e que, embora ainda não predomine um consenso sobre seu feitio futuro exato, cada vez mais assume a natureza de união política. Nos últimos dois anos, o caráter político e supranacional da União foi reforçado com o estabelecimento de uma Política Externa e de Segurança Comum (PESC), que faz da União Européia um ator internacional único com mecanismos efetivos de coordenação para a segurança. Embora ainda em um estágio pouco avançado, a PESC fornece a base necessária para que, cada vez mais, a União Européia “fale de uma só voz”. Com a PESC, a União Européia adquire um peso político maior do que a soma do peso de cada um de seus Estadosmembro e se afirma, portanto, como um ator central na diplomacia mundial. Face à desordem econômica internacional e à desestabilização política por ela provocada, 
a unificação política européia vem fornecer um importante elemento de estabilidade ao sistema internacional, estabilidade que deve ser ainda mais consolidada com a realização da União Econômica e Monetária e a recente introdução da moeda única, o euro, em janeiro de 1999. A PESC representa, portanto, um caso único de junção de objetivos econômicos, políticos e estratégicos, ilustrando a interdependência entre as diferentes estruturas da economia política internacional.

Este artigo discute algumas destas transformações globais desde o ponto de vista da disciplina de Relações Internacionais. Ele inicia considerando como as principais correntes teóricas em Relações Internacionais se posicionam face à questão da globalização, e enfatiza a necessidade de uma análise inspirada na Teoria Crítica e baseada na perspectiva da Economia Política Internacional. Esta se apresenta como a mais adequada para discutir a questão central do debate das ciências sociais hoje: a relação entre Estados e Mercados, entre Economia e Política, e a tensão entre uma economia cada vez mais internacionalizada e um sistema político que segue baseado no Estado-nação.

Após tal introdução teórica, o texto examina as grandes transformações em curso no contexto da globalização econômica, as reformas econômicas dos anos 80 e 90 no sentindo da liberalização das economias nacionais e da integração regional e mundial, assim como seus efeitos sobre o papel do Estado e as relações internacionais. Em seguida, o significado da tendência em direção ao regionalismo é analisado, com o estudo do caso da União Européia e das novas áreas de integração política. A União Européia se apresenta como evidência da relação entre estabilidade econômica e cooperação política.

\section{Teoria internacional e globalização}

\section{I.1. As relações internacionais enquanto disciplina}

A disciplina de Relações Internacionais, em sua curta história enquanto disciplina objeto de estudo acadêmico formalizado, foi marcada pela predominância de duas correntes centrais, o Idealismo, hoje transformado em Institucionalismo Liberal, e o Realismo, reconvertido em Neo-Realismo. ${ }^{1}$ O Institucionalismo Liberal enfatiza o papel das instituições internacionais e as possibilidades de cooperação resultantes da interdependência crescente entre os países. O Realismo, por sua vez, baseia sua análise sobre as estruturas de poder e segurança, o papel dos atores hegemônicos, a ordem e a estabilidade do sistema internacional. ${ }^{2}$

A história da disciplina de Relações Internacionais esteve intimamente ligada aos próprios desdobramentos do contexto internacional: as teorias foram elaboradas para responder às preocupações e problemas vividos em cada época. A primeira corrente teórica que surgiu, o Idealismo, correspondeu ao desejo de evitar conflitos que caracterizou o período após a Primeira Guerra Mundial. Na 
época, dominou o idealismo inspirado na visão da paz perpétua de Kant. Os “quatorze pontos de Wilson”, que serviram de base ao Tratado de Versalhes de 1919, proclamaram a elaboração de uma nova abordagem da diplomacia internacional, com negociações abertas e acordos públicos. Tal visão levou à criação da Sociedade das Nações (S.D.N.), primeira tentativa formal de criar uma organização internacional baseada no princípio da segurança coletiva, visando a mediação de conflitos, com uma estrutura permanente e uma Carta codificada. A disciplina de Relações Internacionais surge em tal contexto, com o objetivo de, através o estudo científico, estabelecer as condições para uma paz duradoura e uma cooperação crescente entre as nações. A disciplina nasce, portanto, com um forte conteúdo normativo, baseada na crença de que a pesquisa deve ter como objeto o que deveria ser, e não o que é.

Após os horrores da Segunda Guerra Mundial e no quadro de formação do antagonismo ideológico da Guerra Fria, o Idealismo encontra-se em um estado quase moribundo. O Realismo afirma-se, então, como uma explicação convincente de um mundo dominado pela competição e pelo conflito. Inspirado na visão de clássicos tais como Tucídides, Maquiavel, Hobbes e Rousseau, os autores realistas, como por exemplo Kenneth Waltz, interpretam a política internacional como uma luta sem fim pelo poder, com raízes na própria natureza humana. Esta foi a visão que caracterizou todo o período da Guerra Fria, e foi cristalizada na ação de políticos como Henry Kissinger, Secretário de Estado dos Estados Unidos durante o governo Nixon, que afirmava que a sobrevivência de uma nação não pode, de maneira alguma, ser colocada em risco. Convictos de que cada Estado tem seus valores, prioridades e crenças, Realistas vêem o Estado como o bem supremo, e não acreditam na existência de uma "comunidade internacional”. A Guerra Fria e a situação de tensão que marcou o período do pós-guerra ilustravam com precisão tais princípios e suposições.

A breve história do desenvolvimento intelectual da disciplina de Relações Internacionais indica, portanto, que esta parece ter sido em grande parte determinada e guiada pelas exigências da realidade internacional. As preocupações de ordem e de segurança acabaram prevalecendo sobre debates mais críticos e análises das estruturas das relações nacionais e internacionais, do questionamento das relações de poder, da formação do conhecimento, e outras questões tratadas pelas ciências sociais. A disciplina também não demonstrava muita preocupação com a análise das relações econômicas internacionais, centrando-se quase exclusivamente nas questões de segurança, política externa e diplomacia. A corrente que mais se preocupou com a análise da relação entre organização econômica e ordem/desordem internacional foi a corrente marxista, que obteve algum respaldo nas décadas de 60 e 70, sobretudo nos anos seguintes à elaboração da teoria da dependência e de sua visão do mundo em termos de centro e periferia. A teoria do sistema mundo, de Gunder Frank, Wallerstein e Arrighi, ganhou vários adeptos. 
No entanto, ela nunca chegou a ocupar um lugar central nas discussões da disciplina de Relações Internacionais. A maioria dos autores segue confinando-se a discussões sobre a ordem política e instituições, deixando os temas da ordem econômica aos economistas e teóricos da regulação. Tal tendência ficou ainda mais forte quando a escola liberal ganha novamente força a partir dos anos 70 e se reestrutura em torno no Institucionalismo Liberal. A Teoria Internacional parecia, de certa forma, legitimar e contribuir a perpetuar o sistema internacional vigente, falhando na tarefa de construção de uma reflexão crítica fundamental na área de ciências sociais. Susan Strange demonstrou como a chamada "teoria dos regimes" que ocupou boa parte dos debates da disciplina nos anos 80 acabou favorecendo o status quo, e permitindo que governos dominem a agenda acadêmica impondo a preocupação com a ordem como valor central, em detrimento de outros valores tais como a justiça ou a democracia. ${ }^{3}$

É nos anos 90 que uma reação ao mainstream surge de forma mais articulada, com novas análises em Relações Internacionais, que se articularam formando a Teoria Crítica e os chamados "Reflectivistas". A Teoria Crítica tem suas raízes no marxismo e se desenvolveu na Escola de Frankfurt nos anos 20, tendo como proponente principal desde 1945 Jürgen Habermas. A Teoria Crítica se afasta da teoria tradicional positivista, que acredita na neutralidade da ciência. Para ela, a teoria não é neutra, ela é normativa, sempre elaborada para alguém e com um objetivo. Não existe a teoria em si, divorciada do tempo e do espaço. As ciências sociais diferem das ciências naturais, e não são independentes de seus objetos de estudo. A origem conceptual da Teoria Crítica pode ser melhor entendida através da distinção que Cox elaborou entre Teoria Crítica e o que ele chama de abordagens de "resolução de problemas". ${ }^{4}$

- A abordagem de resolução de problemas toma o mundo como dado, como ela o encontra, com suas relações de poder existentes e as instituições onde estas se organizam, como marco dado para a ação. O objetivo é fazer com que estas relações e estas instituições funcionem melhor. No campo da Ciência Política, a abordagem de resolução de problemas preocupa-se em analisar o funcionamento e a eficiência de determinadas instituições, arranjos ou sistemas políticos, sem questionar a existência de tais instituições, suas origens, seu papel histórico, e seu potencial de mudança. Em Relações Internacionais, estuda-se temas de política externa, as relações diplomáticas entre países, suas relações econômicas, o funcionamento de instituições internacionais, problemas de defesa, estratégia, ou guerras. Mas não se questiona a ordem internacional que deu origem a tais relações diplomáticas, estratégias ou instituições.

- A Teoria Crítica, em contraste, baseia-se em um questionamento da ordem vigente, no caso, a ordem internacional, mas também a ordem social e a ordem econômica, um questionamento de suas origens e de sua legitimidade. 
O objetivo é considerar possibilidades de mudança em tal ordem. Ou seja, a Teoria Crítica está comprometida com a análise do potencial existente para mudanças e transformações estruturais na ordem internacional e com a construção de estratégias de mudança. Neste sentido, ela contém um elemento normativo a favor de uma ordem internacional distinta.

A Teoria Crítica resgatou a postura de questionamento que esteve ausente de boa parte da literatura de Relações Internacionais, com uma agenda de pesquisa pós-positivista, que desafia o racionalismo das análises realistas e liberalinstitucionalistas. A partir de então, alguns autores, entre os quais destaca-se Alexander Wendt, buscaram desenvolver uma abordagem que falasse tanto aos racionalistas quanto aos Reflectivistas, o que levou à formulação da corrente do construtivismo social. ${ }^{5}$ Sem adotar o relativismo imobilista que carateriza parte das análises ditas "pós-modernas", o construtivismo social tenta conjugar os questionamentos da Teoria Crítica com os ensinamentos da economia política internacional e elementos revigorados do estruturalismo. Assim, ele fornece uma base séria e sólida para, à luz das transformações que o mundo vive no fim deste milênio, elaborar um instrumental teórico que torne a teoria internacional uma teoria à part entière e não mais uma mera produção de soluções para problemas internacionais.

\section{I.2. A economia política das relações internacionais}

A Economia Política considera os quadros historicamente constituídos e as estruturas dentro das quais as atividades econômicas se desenvolvem. Ela parte de um questionamento das atuais estruturas e examina como elas podem estar se transformando, ou como elas poderiam ser transformadas. Nesse sentido, a Economia Política é teoria crítica. Ela considera a mudança histórica enquanto relação recíproca entre estruturas e atores. A Economia Política Internacional, segundo a definição de Gilpin, se interessa pelas causas e efeitos da economia mundial de mercado, como, por exemplo, a existência de estruturas globais de produção, distribuição e consumo, e pelas relações entre mudanças econômicas e mudanças políticas. Com isso, ela possibilita a quebra da tradicional distinção entre o internacional e o doméstico, entre a política e a economia. ${ }^{6}$ As principais diferenças entre as correntes teóricas estão apresentadas na tabela da página seguinte.

A Economia Política Internacional enquanto corrente teórica mantém um grau de parentesco com o neo-estruturalismo, na medida em que ela considera a influência estrutural de forças globais sobre a política. Em vez de enfatizar as negociações interestatais, como faz o institucionalismo liberal, há uma preocupação em considerar a dinâmica do desenvolvimento no contexto do sistema internacional como um todo. No entanto, ao negar a distinção entre níveis de análise, que separa o nacional do internacional, a perspectiva crítica vai além do determinismo 
Tabela 1. As 3 abordagens teóricas em Relações Internacionais

\begin{tabular}{|l|l|l|l|}
\hline TEORIA & $\begin{array}{l}\text { LIBERAL: IDEALISMO E } \\
\text { INSTITUCIONALISMO } \\
\text { LIBERAL }\end{array}$ & REALISMO & $\begin{array}{l}\text { ECONOMIA } \\
\text { POLÍTICA } \\
\text { INTERNACIONAL }\end{array}$ \\
\hline Enfoque & $\begin{array}{l}\text { Interesses; } \\
\text { Cooperação. }\end{array}$ & $\begin{array}{l}\text { Poder; } \\
\text { Segurança. }\end{array}$ & $\begin{array}{l}\text { Economia Política; } \\
\text { Potencial de } \\
\text { transformação. }\end{array}$ \\
\hline $\begin{array}{l}\text { Pressupostos } \\
\text { básicos }\end{array}$ & $\begin{array}{l}\text { Instituições enquanto } \\
\text { determinantes do } \\
\text { comportamento coletivo; } \\
\text { Existência de interesses e } \\
\text { valores universais. }\end{array}$ & $\begin{array}{l}\text { Racionalidade dos } \\
\text { Estados; } \\
\text { Busca do Poder; } \\
\text { Existência de atores } \\
\text { hegemônicos. }\end{array}$ & $\begin{array}{l}\text { Rejeição da } \\
\text { universalidade; } \\
\text { Rejeição da distinção } \\
\text { entre níveis de análise } \\
\text { (política/economia, e } \\
\text { interno/externo). }\end{array}$ \\
\hline $\begin{array}{l}\text { Nível de } \\
\text { análise }\end{array}$ & $\begin{array}{l}\text { Global - ideologia do } \\
\text { "mesmo barco". }\end{array}$ & $\begin{array}{l}\text { Internacional, mas } \\
\text { respeitando a } \\
\text { soberania. }\end{array}$ & $\begin{array}{l}\text { Local; } \\
\text { Global. }\end{array}$ \\
\hline $\begin{array}{l}\text { Atores } \\
\text { considerados }\end{array}$ & $\begin{array}{l}\text { Estados; } \\
\text { Organizações } \\
\text { Internacionais; } \\
\text { Comunidades } \\
\text { Epistêmicas. }\end{array}$ & Estados. & $\begin{array}{l}\text { Estados; } \\
\text { Corporações } \\
\text { Transnacionais; } \\
\text { Organizações } \\
\text { Internacionais; } \\
\text { Movimentos Sociais. }\end{array}$ \\
\hline
\end{tabular}

estruturalista, e estuda a interação entre estruturas sociais domésticas, o Estado e a estrutura internacional como um processo dinâmico. No caso, considera-se como a redefinição do modelo de desenvolvimento e as transformações que acompanham a globalização econômica afetam as reformas políticas nacionais e as estratégias de definição de uma inserção favorável no sistema internacional. Mas, a análise crítica também contempla como um Estado ou uma sociedade são afetados pelas transformações globais e pela sua participação no sistema mundial, quais são as implicações da globalização para a sociedade nacional, e como esta sociedade responde a tais transformações globais. A ênfase é colocada no processo transformativo das relações Estado-sociedade enquanto um processo condicionado pela globalização econômica.

Uma visão crítica da Economia Política Internacional parte de duas presunções. Primeiro, o sistema internacional é uma construção histórica e social, e, portanto, existem diferentes percepções e diferentes soluções. A busca de soluções universais pode ser problemática. Segundo, os Estados não são os únicos atores relevantes no contexto da política global, atores como Organizações NãoGovernamentais (ONGs), Corporações Transnacionais e Organizações Internacionais, ligados através de redes transnacionais eficientes, têm um papel central. Em vez de começar a análise com a observação de como os Estados 
reagem à mudança global, convém estudar como práticas sociais, econômicas, políticas e culturais em várias partes do mundo não só geram problemas estruturais tais como desigualdade, exclusão e destruição ambiental como também limitam as respostas possíveis para reverter tais transformações. A partir de tais suposições, a abordagem crítica analisa as condições históricas que possibilitam o entendimento da atual ordem internacional, as transformações estruturais da Economia Política Internacional - mudança da ordem política, e mudança da ordem econômica - e seus significados políticos, tentando responder à questão básica colocada por Susan Strange, "quem obtém o que, e como?"

\section{Mudanças estruturais e relações internacionais}

Uma discussão crítica da ordem internacional e de seus limites passa necessariamente, como ponto de partida, pela consideração da própria estrutura do sistema internacional. Segundo Susan Strange, existem quatro estruturas da Economia Política Internacional: produção, finanças, segurança e conhecimento. ${ }^{8}$ São estes quatro recursos, interligados entre si, que conferem poder aos Estados e atores no plano internacional. A primeira estrutura é a produção: a capacidade de decidir o que deve ser produzido, como, por quem, com que métodos, com que combinação de fatores de produção; é um recurso indiscutível de poder. A segunda é formada pelas finanças: o poder de controle do crédito. Este vai determinar em boa parte os três outros recursos estruturais. Na economia moderna, não dependemos mais da acumulação de lucros para ter recursos financeiros: os recursos financeiros podem ser criados. Quem tem a capacidade de ganhar a confiança de outros agentes em sua habilidade de criar crédito controla a economia. A terceira estrutura é a da segurança: enquanto existir a possibilidade de conflito violento e de ameaça à segurança pessoal, o ator que oferece segurança ganha poder em outros assuntos também. Por fim, o conhecimento: conhecimento é poder, a capacidade de produzir conhecimento ou controlar o acesso ao conhecimento tem uma enorme influência sobre as outras estruturas da Economia Política Internacional. Hoje, o tipo de conhecimento mais requisitado é a tecnologia. Os centros de tecnologia avançada no mundo são, também, os centros de poder político e econômico.

Estas quatro estruturas da Economia Política Internacional, interligadas entre si, estão sofrendo transformações fundamentais neste final de milênio. Dois processos chaves merecem ser estudados com atenção. O primeiro é a transformação da ordem política internacional com a passagem a uma ordem dita "pós-wetsfaliana”, com a modificação do conceito de soberania. A segunda é a transformação estrutural da Economia Política Internacional causada pela crescente globalização econômica. Estes dois processos de transformação têm um impacto fundamental sobre o papel e o significado do Estado e sobre a própria natureza das relações internacionais. 


\section{II.1. As duas transformações chaves da Economia Política Internacional}

\section{II.1.1. A transformação da ordem política: passagem à ordem política pós-westfaliana}

O Tratado de Westfália de 1648 é freqüentemente citado como o tratado que jogou as bases do sistema de Estado-nação na Europa. ${ }^{9}$ Westfália marcou a mudança da ordem política na Europa: da divisão por religiões que havia caracterizado a Idade Média, passa-se a uma diversidade internacional baseada em uma sociedade de Estados, e cada vez mais a autoridade política se distingue da autoridade religiosa. Reconhece-se a existência de Estados separados e soberanos, e a religião deixa de ser uma justificação legítima para a intervenção ou guerra entre Estados europeus. Os princípios de Westfália - não-intervenção e soberania - forneceram a base da ordem internacional dos últimos séculos, prevalecendo em todo o direito internacional e nos documentos das Nações Unidas. Porém, atualmente, há uma alteração nos padrões de regulação e de intervenção do Estado, ligada a mudanças na ordem internacional. O peso crescente e o novo caráter das relações econômicas transnacionais criaram um contexto mais constringente para a ação do Estado, e novos atores surgiram nas relações internacionais. Três elementos compõem esse quadro de transformações.

i) O desenvolvimento do direito internacional, que atualmente desafia a concepção clássica de soberania. Hoje, existem acordos e regimes internacionais que limitam a soberania dos Estados para proteger valores comuns, como os direitos humanos, ou os chamados "bens comuns da humanidade" tais como o meio ambiente. Cada vez mais, aceita-se missões internacionais ou ações com base no "direito de ingerência”, o direito de intervir diretamente nos assuntos internos de outro país em nome de valores universais. É o caso das missões humanitárias e da assistência eleitoral levadas a cabo pela ONU ou pela União Européia. Também prolifera a prática chamada de "condicionalidade política”, na qual a ajuda e a assistência internacional estão ligadas a critérios como a democracia ou a realização de eleições livres. Por fim, surgem programas de cooperação internacional que vão muito além da soberania e envolvem uma série de atores não somente estatais mas, também, nãogovernamentais. Um exemplo de grande porte é o PPG7 da Amazônia, o Programa Piloto para a Preservação da Amazônia que funciona com fundos do G7 e do Banco Mundial e com a participação de vários Estados, organismos internacionais, Organizações não-Governamentais e setores da sociedade civil.

ii) O papel das grandes corporações internacionais, que não necessariamente respondem a critérios nacionais: empresas como a Shell ou a Mitsubishi atuam como atores transnacionais e têm poder de influência comparável ou superior ao de alguns Estados. Certos Estados são, na verdade, Estados fantoches, 
dominados por outros Estados, com pouca autonomia política, como o Líbano, ou controlados por instituições internacionais. A atuação das grandes corporações pode ter um alcance bem mais amplo e uma influência mais considerável no curso das relações internacionais. As corporações transnacionais se tornaram atores políticos fundamentais com relações de natureza política com a sociedade civil.

iii) O crescimento do número e da área de atuação das Organizações NãoGovernamentais: as ONGs desafiam a noção clássica de soberania ao atuarem em áreas nas quais os Estados muitas vezes são deficientes, e ao formarem alianças transnacionais com outras organizações e atores. No Brasil, é bastante visível a atuação de organizações de direitos humanos como a Anistia Internacional, criticando o governo por casos como Carandiru, o massacre de Eldorado dos Carajás, ou o papel de ONGs ambientalistas tais como o Greenpeace ou os Amigos da Terra na divulgação do assassinato de Chico Mendes e das queimadas na Amazônia. Cada vez mais, as relações internacionais são feitas pelos atores não-governamentais.

\section{II.1.2. A globalização econômica}

O outro processo de transformação que vem afetando de maneira fundamental as bases das relações internacionais é a globalização econômica acentuada neste final de século. A globalização deve ser entendida como um processo, um padrão histórico de mudança estrutural, mais do que uma transformação política e social já plenamente realizada. Ela é um fenômeno ao mesmo tempo amplo e limitado: amplo, porque ela cobre transformações políticas, econômicas, e culturais ; limitado, porque não se trata de um processo completo e terminado, e ele não afeta a todos da mesma maneira. O processo de globalização é caracterizado pela intensa mudança estrutural da economia internacional, com o peso crescente de transações e conexões organizacionais que ultrapassam a fronteira dos Estados. Os principais componentes dessa mudança são:

i) a globalização da produção e do comércio: a globalização da produção pode ser entendida como a produção de bens e serviços em mais de um país e segundo uma estratégia global de vendas voltada para o mercado mundial.$^{10}$ O processo de reestruturação da produção começou nos anos 70, no contexto de crescente competição internacional e inovações tecnológicas, e ele foi acelerado nos anos $80 \mathrm{com}$ a queda nas taxas de crescimento e a recessão que muitos países conheceram. Hoje, nota-se uma mundialização da atividade empresarial, tanto na área industrial como na área de serviços, com o papel crescente das grandes corporações transnacionais (CTNs). O número de CTNS cresceu de 3.500 em 1960 para 40.000 em $1995 .{ }^{11}$ 
Houve, também, uma mudança no caráter do comércio. Mais do que uma troca de produtos entre sistemas produtivos domésticos, o comércio hoje é cada vez mais um fluxo de produtos entre redes de produção que são organizadas globalmente e não nacionalmente. As mercadorias são criadas através da integração de processos de produção levados a cabo em uma multiplicidade de territórios nacionais. A inclusão ou exclusão de um território nestas redes de produção depende da decisão de agentes privados. Os Estados podem tentar tornar seus territórios mais atraentes, mas eles não podem ditar a estrutura destas redes de produção global. Hoje, uma grande parcela do comércio internacional, entre 25 e $40 \%$, é na verdade comércio intrafirma. Quando um bem ou serviço vai de uma a outra filial de CTN, a operação é contabilizada como comércio internacional. Na verdade, trata-se do movimento de uma economia global, na qual existem bens e serviços globais, vendidos no mundo inteiro.

ii) A globalização das finanças: os mercados financeiros globais têm desempenhado um papel importante na construção da estrutura e da dinâmica da emergente ordem político-econômica. Alguns autores acreditam que é na área financeira que a globalização tem sido mais intensa, e que esta é a grande novidade do capitalismo no final do século XX. Desenvolvimentos tecnológicos nas comunicações também ajudaram a globalizar as finanças: hoje, existem moedas globais, bancos globais, assim como um sistema de crédito global. As transações de câmbio cresceram de uma média de US\$ 600 bilhões por dia no final dos anos 80 a US\$ 1 trilhão por dia em 1993. O volume de transações financeiras vale 40 vezes mais do que o volume de comércio de mercadorias. As finanças se tornaram separadas da produção, e são hoje um poder independente, o que significa a preponderância de interesses financeiros imediatos sobre considerações de desenvolvimento a longo-prazo.

Os mercados financeiros estão adquirindo uma crescente autonomia em relação aos Estados: o capital move-se de um país ao outro em busca do retorno máximo, afetando a capacidade de os Estados administrarem suas economias. O poder de controle dos bancos centrais sobre o valor de suas moedas é reduzido, o que limita a eficácia das políticas monetárias e fiscais dos governos. Com os capitais especulativos, há menos controle sobre taxas de câmbio, e uma maior volatilidade cambial. Fred Block fala da "ditadura dos mercados financeiros internacionais": todo Estado que iniciar uma política julgada inapropriada será punido pela desvalorização de sua moeda e pelo acesso dificultado ao capital. ${ }^{12}$ Os recentes acontecimentos na bolsa de valores e seu impacto imediato no Brasil são uma boa demonstração desse fenômeno. Hoje, a globalização financeira tende a promover uma crescente “internacionalização” dos Estados. Para O’Brien, é o “fim da geografia”: os movimentos de capital hoje têm uma autonomia geográfica total e não obedecem a critérios nacionais. ${ }^{13}$ 
iii) Uma mudança no modelo de acumulação e de produção: por fim, o modelo de acumulação e produção evoluiu com a passagem ao "pós-fordismo". O modelo fordista de produção era um sistema de acumulação baseado na produção e no consumo de massa. Ele foi criado nos anos 30 nos Estados Unidos e se espalhou pelo mundo após a Segunda Guerra Mundial. Ele se caracterizava por uma aliança entre o Taylorismo como modo de organizar o trabalho, com uma nítida separação entre os aspectos manuais e intelectuais do trabalho, e, de outro lado, relações contratuais rígidas entre capital e trabalho - contratos de trabalho de duração indeterminada com diversas vantagens, convenções coletivas, legislação de proteção social, e outros mecanismos assegurados pelo Estado de bem-estar social. O sistema fordista foi a base do crescimento do após-guerra, garantindo ganhos de produtividade e aumento nos níveis de vida, o que por sua vez assegurava um alto patamar de consumo e estimulava o crescimento. ${ }^{14}$

Este modelo foi chamado de capitalismo organizado, ou de liberalismo embebido (embedded liberalism): um sistema econômico com relativa liberdade para o capital global estava embebido em um corpo social, de instituições, normas, regulamentações, que comprometiam os Estados industrializados a insular e proteger os seus cidadãos, ao menos parcialmente, do custo de tal sistema. ${ }^{15}$ Como vimos, tal ideologia deve muito ao contexto histórico em que foi elaborada: a Segunda Guerra Mundial e seus efeitos devastadores levaram os governos a pensar que uma melhor proteção social de seus cidadãos seria um meio de evitar os traumas políticos das décadas anteriores, assim como de afastar a tentação comunista.

No entanto, tal modelo começa a demonstrar sinais de fraqueza no final dos anos 60, com um declínio no crescimento da produtividade e uma crise na organização do trabalho. Aparece uma contradição entre a globalização da produção e dos mercados e o caráter nacional da regulação do trabalho. Nos anos 80 , os sinais de crise estavam presentes: taxas mais lentas de crescimento da produção, diminuição das taxas de produtividade e crescimento do desemprego. O modelo fordista começou a ser considerado excessivamente rígido. Com o movimento em direção a uma economia mais baseada na informação e na tecnologia de ponta, outros modos de organização do trabalho surgem. O Fordismo tende a ser substituído por modelos pós-fordistas, mais “flexíveis”, ancorados em informação, serviços e alta tecnologia, com os exemplos notáveis dos Estados Unidos e da Grã-Bretanha.

Hoje, estamos nos movendo do que autores chamam de capitalismo organizado, no qual o Estado tinha um grande papel regulador, para um regime de acumulação flexível, no qual as políticas de emprego são flexíveis e toda a ênfase é colocada na competitividade. Este atual modelo tem uma estrutura de produção que segue um modelo centro-periferia: um centro relativamente pequeno de empregados permanentes que são encarregados de tarefas como pesquisa, finanças e organização tecnológica, e uma periferia que compõe o processo de produção e 
se ajusta às decisões do centro, com um uso constante do trabalho temporário. Tal evolução questiona e ameaça as conquistas dos trabalhadores e as leis sociais elaboradas nos tempos do Estado de bem-estar social, colocando sérios desafios à estabilidade social.

\section{II.2. Os efeitos da globalização nas relações internacionais e no papel do Estado}

\section{II.2.1. Significado da globalização econômica para as relações internacionais}

As transformações globais que redesenham a ordem política e econômica internacional têm um impacto considerável tanto no papel do Estado quanto na própria natureza das relações internacionais. Em primeiro lugar, há uma alteração nos padrões de regulação e de intervenção do Estado, ligada a mudanças na ordem internacional. O peso crescente e o novo caráter das relações econômicas transnacionais criaram um contexto mais constringente para a ação do Estado. Hoje, a riqueza e o poder são cada vez mais gerados por transações privadas que acontecem além das fronteiras nacionais mais do que dentro delas. Com isso, torna-se difícil manter a imagem do Estado como o ator principal a nível global, e as relações internacionais distanciam-se da imagem de relações de poder entre os Estados, como enfatizavam os Realistas: cada vez mais, trata-se da lógica privada da economia global.

Nos tempos coloniais, a conquista de territórios, e a ação militar garantiam em parte o poderio econômico de um país. A expansão territorial era uma forma de controlar novos recursos produtivos, matérias-primas, bens e mão-de-obra. $\mathrm{O}$ poder econômico nacional era, de certa forma, a base do poder político e militar. Hoje, redes de produção globais tornam os ganhos ligados à conquista territorial pouco relevantes. $\mathrm{O}$ acesso ao capital e à tecnologia depende de alianças estratégicas com os que controlam as redes de produção global, mais do que do controle de algum território em particular. Em uma economia global, na qual existe uma superabundância de mão-de-obra, o controle de vastos territórios e populações pode até vir a representar um fardo mais do que um ativo.

Por outro lado, a globalização contribuiu para transformar o contexto ideológico das relações internacionais. Durante as décadas de 50 a 70, o desenvolvimento era concebido como crescimento com redistribuição e solidariedade, ao menos no nível de discurso. O Estado ocupava um papel central nas estratégias de desenvolvimento, sendo no Terceiro Mundo o motor do desenvolvimento. Nos anos 80, com a crise da dívida e a recessão, um consenso liberal começa a emergir, com a chegada de Thatcher e Reagan aos governos da Grã-Bretanha e dos Estados Unidos. Os novos líderes conservadores criticam o keynesianismo, o papel excessivo do Estado na economia, e citam como evidência 
o fracasso econômico de países tradicionalmente intervencionistas. Eles divulgam a idéia de que o subdesenvolvimento é antes o resultado de políticas econômicas distorcidas pela intervenção do Estado do que da estrutura do sistema internacional, como pretendiam os dependentistas ou os marxistas. Criticou-se as políticas de substituição das importações e o intervencionismo do Estado. O Estado é visto como estruturalmente impróprio para as tarefas de, diretamente, produzir bens produtivos e distributivos.

Tabela 2. Mudanças na Percepção do Desenvolvimento 1960-1990 ${ }^{16}$

\begin{tabular}{|c|c|c|}
\hline & Anos 60 e 70 & Anos 80 e 90 \\
\hline Contexto Histórico & $\begin{array}{l}\text { OPEC e formação de Cartéis; } \\
\text { Nacionalizações; } \\
\text { Solidariedade com o Terceiro } \\
\text { Mundo; } \\
\text { Esforços para implantar a } \\
\text { Nova Ordem Econômica } \\
\text { Internacional. }\end{array}$ & $\begin{array}{l}\text { Recessão e crise da dívida; } \\
\text { Thatcherismo e Reaganismo; } \\
\text { Monetarismo; } \\
\text { Ajuste Estrutural promovido } \\
\text { por FMI e Banco Mundial. }\end{array}$ \\
\hline $\begin{array}{l}\text { Premissas Básicas do } \\
\text { Pensamento }\end{array}$ & $\begin{array}{l}\text { Obstáculos estruturais ligados } \\
\text { à desigualdade do sistema } \\
\text { internacional; } \\
\text { Diferenças fundamentais } \\
\text { entre países desenvolvidos e } \\
\text { países em desenvolvimento. }\end{array}$ & $\begin{array}{l}\text { Obstáculos ligados à má } \\
\text { administração do governo; } \\
\text { Monoeconomia } \\
\text { (monoeconomics). }\end{array}$ \\
\hline $\begin{array}{l}\text { Definições do } \\
\text { Desenvolvimento }\end{array}$ & $\begin{array}{l}\text { Crescimento com } \\
\text { distribuição; } \\
\text { Provisão de necessidades } \\
\text { básicas. }\end{array}$ & $\begin{array}{l}\text { Crescimento com eficiência; } \\
\text { Inflação baixa, estabilidade } \\
\text { monetária. }\end{array}$ \\
\hline Recomendações Políticas & $\begin{array}{l}\text { Estado desenvolvimentista; } \\
\text { Acesso facilitado às finanças } \\
\text { internacionais; } \\
\text { Substituição de importações; } \\
\text { Acesso comercial preferencial } \\
\text { para países em } \\
\text { desenvolvimento; } \\
\text { Gastos governamentais } \\
\text { elevados; } \\
\text { Regulação e controle de } \\
\text { Investimentos Externos } \\
\text { Diretos (IED). }\end{array}$ & $\begin{array}{l}\text { Papel reduzido para o Estado; } \\
\text { Privatizações; } \\
\text { Restrições monetárias; } \\
\text { Liberalização do câmbio; } \\
\text { Promoção de exportações; } \\
\text { Liberalização comercial; } \\
\text { Disciplina fiscal; } \\
\text { Liberalização dos } \\
\text { Investimentos Externos } \\
\text { Diretos (IED). }\end{array}$ \\
\hline
\end{tabular}


John Williamson foi quem primeiro denominou essas idéias de Consenso de Washington. O Consenso de Washington pode ser definido como um conjunto de políticas macroeconômicas, reformas estruturais liberalizantes, tais como liberalização do comércio, privatização das empresas estatais, desregulamentação dos mercados, reformas fiscais, promoção de investimentos estrangeiros, assim como regras de condicionalidade aplicadas de forma cada vez mais padronizada em vários países e regiões. ${ }^{17}$ Após décadas marcadas pelo desenvolvimentismo e várias experiências de política heterodoxa, o clima internacional na década de 1990, principalmente na América Latina, foi marcado pela adoção generalizada do Consenso de Washington e de políticas de ajuste estrutural, com o objetivo de obter o apoio dos países desenvolvidos e dos organismos internacionais. Hoje, este conjunto de políticas tende a ser visto como sendo de validade universal, levando a um estreitamento das opções de política econômica. Parece haver pouca perspectiva até para governos de esquerda implementarem políticas econômicas diferentes e independentes, o que restringe as estratégias nacionais autônomas.

\section{II.2.2. Impacto da mudança do papel do Estado}

Em segundo lugar, com a globalização, há uma perda da capacidade do Estado de conduzir seus objetivos políticos de maneira autônoma. O mercado parece estar se libertando dos laços das sociedades nacionais. O Estado está cada vez mais subordinado às exigências da economia global. Hoje, o critério central na economia é a competitividade, e, em nome da competitividade, desmantelam-se arranjos Estado-sociedade. Há um movimento em direção à desregulamentação, à privatização, à restrição da intervenção pública nos processos econômicos. Com isso, os Estados deixam de ser um intermediário entre forças externas e forças internas para se tornarem, de certa forma, agências de adaptação das economias domésticas às exigências da economia global. Para Phil Cerny, o Estado de bemestar social nos países desenvolvidos foi substituído pelo Estado competidor, um Estado que intervém para reestruturar indústrias, promover a pesquisa e o desenvolvimento, e liberalizar ou desregulamentar setores anteriormente protegidos da competição internacional. ${ }^{18}$

Face a esse cenário de globalização, a questão que se coloca é de saber se o Estado será capaz de regular, controlar, ou ao menos disciplinar de alguma forma estes fluxos econômicos globalizados. A reforma do Estado aumentará sua capacidade de promover políticas de desenvolvimento sustentáveis? Nesse ponto existe, é claro, uma grande polêmica. No caso do Brasil, por exemplo, a reforma do Estado tem como objetivo declarado central a transição de um Estado intervencionista para um Estado que se quer “coordenador”. ${ }^{19}$ Porém, no quadro da escassez de recursos, da crise fiscal do Estado, a tendência tem sido em direção a contenção dos recursos destinados as políticas sociais, de educação, saúde, meio 
ambiente ... A tendência foi acentuada com a influência da crise internacional que atingiu primeiro a Ásia, a Rússia, e, agora, o próprio Brasil, levando à adoção de medidas que afetam não só a política fiscal mas a capacidade do Estado de realizar políticas públicas, de promover o desenvolvimento sustentável e de investir nas áreas de bens públicos. Isso também deixa o Brasil ainda mais dependente dos recursos externos e projetos internacionais. Além disso, a eficiência dos órgãos do governo, que já é limitada, poderá ser deteriorada com a reforma fiscal, pelo menos a curto prazo. Existem riscos de fraqueza institucional.

Uma outra área que demonstra a perda de controle do Estado sobre temas anteriormente de competência nacional é a questão dos critérios sociais e ambientais. Hoje, cada vez mais, temas como a proteção ambiental e os direitos dos trabalhadores são discutidos em foros internacionais. Como diferenças nacionais no que diz respeito a normas de proteção ambiental e nos custos envolvidos na proteção social têm um impacto evidente sobre a competitividade, existe um movimento crescente em direção à tentativa de harmonização de tais critérios. Pressionados por seus trabalhadores e agricultores ameaçados pela concorrência internacional, governos dos países desenvolvidos condenam países como a China, cujos produtos são muito competitivos a nível internacional, por seus níveis salariais baixíssimos, pelo uso do trabalho dos prisioneiros políticos, do trabalho infantil, e pelo não-respeito ao meio ambiente. Tais práticas tornam os custos de produção bem inferiores àqueles dos países desenvolvidos com normas ambientais e proteção ao trabalhador mais avançada. Há um movimento progressivo em direção à consideração dos processos e métodos de produção nas discussões internacionais sobre comércio, e não mais unicamente do produto acabado. ${ }^{20} \mathrm{O}$ tema dos critérios sociais e ambientais promete ser um item de controvérsia durante a "Rodada do Milênio” da Organização Mundial do Comércio (OMC), a ser iniciada em novembro de 1999. O fato de que temas como a proteção ambiental e os direitos dos trabalhadores sejam cada vez mais discutidos no âmbito de organizações econômicas internacionais mostra a perda de controle dos Estados em áreas que antigamente eram definidas segundo critérios exclusivamente nacionais.

\section{Ordem econômica e estabilidade internacional}

\section{III.1. A estrutura da Economia Política Internacional}

Esta breve análise mostrou que as estruturas da Economia Política Internacional estão sofrendo modificações fundamentais e se encontram hoje em estágios bastante diferenciados de (des)organização e (des)regulação. No caso das finanças, os fluxos permanecem desregulados. Não existe uma verdadeira estrutura que regule fluxos financeiros e o sistema monetário, apenas instituições como FMI e Banco Mundial, muitas vezes acusadas de cumprir a função de assistir 
os Estados mais poderosos no controle e domínio do sistema. As finanças são mais do que nunca o laço mais frágil da economia internacional: fluxos de capital especulativos e voláteis representam uma fonte de instabilidade global, com conseqüências políticas diretas. No âmbito monetário, desde o fim da convertibilidade do dólar em ouro, predomina o "não-sistema” das taxas flexíveis, um sistema instável que acaba repercutindo sobre os fluxos de comércio e investimentos. Não existe um sistema monetário estável que possa oferecer liquidez, ajuste e confiança, as três questões básicas que o sistema monetário se propõe de solucionar. ${ }^{21}$ Apenas no caso do comércio é que o sistema parece ter uma base verdadeiramente multilateral e organizada. A Organização Mundial do Comércio (OMC), que substituiu o GATT em 1995, tem como objetivo liberalizar o comércio de acordo com regras multilaterais preestabelecidas, promovendo a harmonização das regras comerciais. A OMC também possui mecanismos de resolução de disputas comerciais e métodos para forçar a implementação de suas decisões, e tende a cobrir um número crescente de áreas: bens, serviços, propriedade intelectual, tecnologia e telecomunicações. O processo de integração comercial regional também vem avançando firmemente, com a formação de blocos, uniões aduaneiras e áreas de livre-comércio. No caso da União Européia, um processo de integração que teve início como integração comercial, hoje, evoluiu-se para uma união política.

\section{III.2. Liberalismo desembebido}

Embora a estrutura do comércio esteja relativamente bem institucionalizada e regulada, as bases da Economia Política Internacional permanecem ameaçadas pelas incertezas geradas pelo caos financeiro e monetário. O fim do que Ruggie chamou de "compromisso do liberalismo embebido" trouxe conseqüências políticas e estratégicas que ainda não estão plenamente claras, mas que evidenciam a ligação entre segurança econômica e estabilidade da ordem internacional.

Na época do após-guerra, Bretton Woods representou a própria institucionalização da relação entre economia e segurança ou estabilidade política: a organização da economia internacional com base no compromisso do "liberalismo embebido” seria a base da segurança do campo ocidental. Tal compromisso era, na verdade, uma forma de multilateralismo, consistente com a manutenção da estabilidade doméstica, na qual as sociedades aceitavam as mudanças e evoluções requeridas pela liberalização internacional. Em troca, os efeitos da liberalização eram amenizados através da ação social e econômica dos governos com o estabelecimento do Estado de bem-estar social. Havia a consciência da necessidade de um equilíbrio entre estabilidade doméstica e normas internacionais. O grande sucesso dos anos do após-guerra foi justamente o de construir uma ordem internacional que também permitiu o alcance de maneira harmoniosa dos objetivos dos Estados de bem-estar social. Mas é claro que este trade-off foi possível, em 
grande medida, pelo contexto da Guerra Fria, que oferecia a ameaça externa fundamental para harmonizar posições e alcançar compromissos. ${ }^{22}$

A situação atual é radicalmente diferente. Vivemos hoje em um mundo quase homogeneizado, com o sistema de mercado dominando totalmente as relações econômicas e com a adoção quase universal da democracia como sistema político, ao menos formalmente. Não existe mais uma ameaça externa capaz de operar tal junção dos objetivos econômicos com os objetivos politico-estratégicos a nível global. No entanto, a instabilidade política gerada por falta de regulação do sistema internacional poderia resultar em ameaça à segurança do mundo como um todo. A crise econômica da Ásia, cujas conseqüências ainda não realizamos totalmente, poderia estar na origem de uma desestabilização regional, que poderia ser acirrada com a corrida nuclear entre Índia e Paquistão. A onda de protestos que seguiu a adoção do pacote recessivo na Indonésia em 1997 e a subseqüente queda de Suharto demonstram a necessidade de privilegiar uma visão mais política da ordem internacional, pois se os efeitos da volatilidade do capital podem abalar um regime totalitário e repressivo, o contrário, a queda de regimes democráticos, também pode ocorrer. ${ }^{23}$

Nesse contexto, análises recentes enfatizam a necessidade de reformar a ordem econômica internacional, de se pensar em um "Bretton-Woods II". Uma delas aponta justamente, como prioridade absoluta, o reconhecimento pelo presidente Clinton da conexão entre segurança econômica e segurança nacional. ${ }^{24}$ No mundo de hoje, globalizado porém fragmentado, marcado por enormes injustiças, com instabilidade financeira, destruição do meio ambiente, migração em alta escala, desemprego e pobreza, a autoridade dos Estados parece não ter capacidade de resolver estes problemas de maneira adequada. ${ }^{25}$ Há uma necessidade de reforçar a estrutura política internacional para possibilitar a resolução de questões que, cada vez mais, ultrapassam as fronteiras nacionais.

Com a crescente interdependência entre os países, a natureza da política econômica mudou. Estados perseguindo objetivos políticos nacionais entram em conflito através dos mecanismos de ligação entre as economias nacionais. Quando muitos Estados buscam realizar seus objetivos econômicos em um mundo interdependente e não coordenam suas políticas econômicas, estas podem estar em contradição. O problema é, portanto, um problema político de como chegar à cooperação internacional e construir um sistema econômico estável. ${ }^{26}$ Falta um arcabouço político que opere como controle sobre os fluxos econômicos transnacionais. Os próprios organismos internacionais que enfatizavam as reformas de mercado hoje tendem a destacar a importância da regulação estatal e da cooperação internacional. O relatório do Banco Mundial de 1997, Reviving the State, também coloca que "a ênfase atual sobre o papel do Estado lembra outra era, quando o mundo emergia dos estragos da Segunda Guerra Mundial”, com a implicação de que estaríamos vivendo outro momento crucial na evolução da 
arquitetura internacional. ${ }^{27}$ No entanto, as tentativas de reestruturar a ordem econômica têm tido pouco êxito, como demonstrou o recente fracasso da tentativa de elaborar restrições aos movimentos de capitais especulativos.

Em tal contexto de incertezas e grande vulnerabilidade da fluidez dos fluxos econômicos, com o sentimento dominante de que o mundo está fragmentado, a integração regional parece ser o único processo de caráter unificador e estabilizador. A integração regional assume não só a função de garantia de mercados e parceria econômica: os blocos econômicos caminham também em direção a formas de união política, respondendo à necessidade de garantir a estabilidade da ordem internacional. É neste contexto que a União Européia se destaca como um processo com importantes implicações para a ordem internacional.

\section{III.3. O regionalismo na ordem internacional: o exemplo da União Européia}

Dentre os vários processos de integração em andamento, a União Européia se destaca por vários motivos. Primeiro, pelo seu caráter pioneiro e, nos seus primórdios, na época da criação da Comunidade Européia para o Carvão e o Aço (CECA) em 1952, quase que revolucionário, significando uma ruptura com o passado de rivalidades e conflitos armados entre os seus dois principais iniciadores, França e Alemanha. Segundo, pelo alto grau de integração econômica e monetária já alcançado. A União Européia é o único processo de integração regional que inclui a livre circulação de pessoas, constituindo um verdadeiro mercado comum. O recente lançamento da moeda comum, o euro, e a adoção de uma política monetária unificada devem integrar ainda mais economias que já são altamente interdependentes e fortalecer o poderio econômico do velho continente. Finalmente, a União Européia se destaca pela natureza verdadeiramente política de seu processo de integração.

A União repousa sobre instituições tanto supranacionais como intergovernamentais, entre as quais as principais são a Comissão, órgão executivo, o Conselho de Ministros, a Corte de Justiça e o Parlamento, que representa os cidadãos dos 15 países membros. Em várias áreas, tais como a política comercial, a política de cooperação, e, mais recentemente, a política interna, as políticas já são, em boa parte, estabelecidas a nível europeu. O nível mais avançado de integração foi implantado em $1^{\circ}$ de janeiro de 1999 com a introdução do euro, a moeda única européia, e a concretização da União Econômica e Monetária (UEM), que levará a uma convergência macroeconômica cada vez maior dos países membros. ${ }^{28}$ Assim, a União adquiriu para si própria muitos dos atributos do Estado, em um processo avançado de "europeização" da vida pública.

O estabelecimento de uma Política Externa e de Segurança Comum (PESC) pelo Tratado de Maastricht vem reforçar tal dimensão. ${ }^{29}$ A experiência da PESC se insere claramente no âmbito dos esforços para estabilizar o sistema político 
internacional. Neste final de século, a grande questão que se coloca na agenda internacional é a da possibilidade de desenhar uma arquitetura mundial que ofereça uma proteção contra os efeitos perversos do "capitalismo de cassino" denunciado por Susan Strange. ${ }^{30}$ A atual crise internacional relançou o debate sobre o controlar dos fluxos financeiros e de suas possíveis conseqüências políticas e estratégicas.

Uma hipótese que pode ser delineada é de que, na falta de uma maior regulação dos fluxos econômicos internacionais, a União Européia poderá vir a privilegiar, cada vez mais, o aprofundamento do processo de integração e o caminho da união política plena como garantia da estabilidade e de ordem que inexistem a nível mundial. Para Cerny, uma característica central da nova ordem mundial será justamente a desvinculação entre conflitos locais e regionais de um lado, e a estabilização do conflito no sistema como um todo. ${ }^{31}$ Assim, o regionalismo e a integração não são somente meros instrumentos utilitários para reconciliar interesses do Estado, resolver questões de segurança e defender identidades locais contra desafios e ameaças globais: na era após-Guerra Fria, tornaram-se mecanismos fundamentais de estabilização da ordem mundial. ${ }^{32}$ Afirmando sua influência diplomática e estratégica através da unificação da política externa de seus membros, a União Européia seguramente poderá expandir a relevância internacional que o seu peso econômico já lhe garante. Os recentes esforços para dotar a União Européia de capacidade militar de intervenção e de reforçar o papel da Europa dentro da OTAN, reafirmados pelos líderes europeus, poderiam, finalmente, pela primeira vez desde a Segunda Guerra Mundial, dar à Europa uma voz independente em questões militares. ${ }^{33}$

A PESC representa, portanto, um desafio importante para a União Européia. Por seu peso econômico e seu papel histórico na diplomacia mundial, os países da Europa têm a oportunidade, através da PESC, de reconquistar uma posição hegemônica no sistema internacional. Com a entrada em vigor do Tratado de Amsterdã em 10 de Maio de 1999, a União Européia passará, a partir de junho, a contar com uma espécie de Ministro do exterior da Europa, o Alto Representante para a Política Externa e de Segurança Comum, reforçando a imagem de uma Europa unida, “falando com uma só voz”. A PESC também possui implicações significativas para a ordem internacional, uma vez que ela reforça a estabilidade no continente europeu e diminui as incertezas em um contexto internacional marcado por fortes turbulências e pelo impacto político dos choques financeiros. O sucesso da PESC é ainda incerto, dependendo, em parte, das condições da realização da expansão da União com a adesão dos países da Europa Central e Oriental. A “Agenda 2000” da União Européia, apresentada em Julho de 1997, apresenta a estratégia para reforçar o crescimento, a competitividade e o emprego, assim como para estender as fronteiras da União até Ucrânia, Bielorússia e Moldávia através da expansão de seus membros. De acordo com o calendário recentemente definido, Hungria, Polônia, Estônia, República Checa e Eslovênia, os países que mais se 
aproximam dos critérios estabelecidos, poderão ingressar na União já a partir de 2003. Segundo Jacques Santer, a expansão da União Européia, que ele define como "uma oportunidade histórica para a Europa”, será financiada através de "um verdadeiro Plano Marshall para os países da Europa Central e Oriental”. ${ }^{34}$ Resta a saber se a União terá a habilidade de incorporar novos membros e, simultaneamente, reforçar a dimensão comunitária de sua política externa. Tal tarefa será, certamente, dificultada caso a situação da Rússia continue se degradando e afete seus vizinhos da Europa Central e Oriental. Uma posição externa comum aparece como ainda mais urgente no presente contexto de guerra na Iugoslávia e da intervenção da OTAN em Kosovo. Como a União Européia falhou na elaboração de uma solução européia à questão de Kosovo, como já havia falhado na Bósnia, agora resta-lhe o imperativo de assumir uma posição dinâmica no processo de reconstrução da região e de consolidação da paz.

Em todo caso, União Européia constitui um sistema único e complexo de tomada de decisão, um laboratório dinâmico de experiências políticas supranacionais que está redefinindo o caráter da política e do poder estatal. Majone chega a falar da União como um verdadeiro "Estado regulador", cuja função central é corrigir falhas de mercado e externalidades e suprir os bens comuns como leis, ordens ou proteção do meio ambiente, que, hoje, não dependem mais unicamente do poder nacional. Para Majone, o Estado regulador europeu do futuro poderá vir a ser menos um Estado no sentido tradicional da palavra do que uma teia de redes de instituições reguladoras nacionais e supranacionais ligadas por valores e objetivos divididos e um estilo comum de fazer política. ${ }^{35}$ A experiência da adoção da PESC deve ser considerada no âmbito deste contexto híbrido e inovador no qual as instituições desempenham um papel interventor visando o equilíbrio em um processo que é mais que um regime internacional, mas menos que uma federação de Estados unidos.

Por fim, deve ser assinalada a importância da experiência européia para o Brasil e para o processo de integração no âmbito do Mercosul. Por um lado, a integração da UE pode ser vista como instrumento de medida para avaliar o Mercosul. Embora ainda seja caracterizado por um baixo grau de integração política, o Mercosul, em virtude do desenvolvimento de sua inserção internacional, leva a uma demanda crescente por um maior grau de coordenação, quer na arena subregional, quer na mundial. ${ }^{36}$

A crescente presença de empresas européias nos países do Mercosul indica um desejo de fortalecimento dos laços econômicos por parte da UE. ${ }^{37}$ A realização da Cimeira América Latina-União Européia em 28 e 29 de junho próximos no Rio de Janeiro contribuirá para reforçar os distintos diálogos institucionalizados hoje existentes entre as duas regiões. O encontro de Chefes de Estado e Governo, precedido por uma Reunião de Ministros de Relações Exteriores ALC-UE contemplará assuntos políticos, assuntos econômico-comerciais e assuntos culturais, educativos e humanos. O encontro poderia ser o primeiro passo em direção 
à negociação de uma zona de livre-comércio entre a UE e o Mercosul, conforme anunciado pelo Chanceler alemão Gerard Schroeder, atual presidente da União Européia. As bases para as discussões de uma zona de livre-comércio já estão estabelecidas pelo acordo global da UE com o Mercosul firmado em 1995, cujo artigo 4 estabelece que ambas as partes prepararão uma associação política e econômica.

\section{Conclusão}

Este texto tentou apresentar uma visão crítica do atual panorama internacional. Baseado na abordagem da Economia Política Internacional e inspirado nos pressupostos da Teoria Crítica, ele definiu e analisou algumas das principais transformações em curso no sistema internacional, ligando sempre fatores políticos e fatores econômicos e questionando a relação entre Estados e mercados. As transformações atuais estão redefinindo as próprias bases da política e da economia, modificando o papel do Estado e o significado da soberania. Na verdade, Estado e soberania são conceitos que foram construídos socialmente, em uma determinada época histórica. Tanto Estado quanto soberania são conceitos dinâmicos, e não estáticos: é compreensível que eles evoluam acompanhando as mudanças estruturais dos sistemas políticos e econômicos internacionais. Ademais, não há uma norma universal que diga que os Estados são os únicos agentes da mudança política. A globalização vem justamente demonstrando a importância crescente de outros atores na ordem mundial, sejam eles corporações transnacionais ou ONGs. Assim, o debate sobre a globalização é fundamental. Os países, as políticas, os povos, são cada vez mais afetados por fatores internacionais e forças globais. No entanto, deve ser enfatizado que a globalização se dá de maneira desigual e heterogênea, marginalizando uma boa parte da população mundial que não é integrada na economia global. Se, por um lado, ela homogeneiza práticas econômicas, sociais e culturais, por outro lado, ela fratura e dualiza entre os segmentos integrados e globalizados e os excluídos. Uma reflexão crítica sobre a ordem mundial deve partir do questionamento dos fenômenos supostamente globais.

Por fim, o reconhecimento da existência da globalização não diminui a importância de se fixar metas políticas locais, regionais, nacionais. Há espaço para a construção de estratégias alternativas de ação coletiva. Muitas vezes, o impacto do papel do Estado tende a ser exagerado. ${ }^{38}$ A ditadura das finanças denunciada por Block na verdade se aproxima mais de uma situação de refém-mútuo. A operação do sistema financeiro internacional se tornaria caótica sem políticas fiscais e monetárias responsáveis por parte dos atores internacionais. As finanças internacionais podem punir Estados que desviam seu comportamento da norma padrão, mas a longo prazo seus lucros e retornos dependem da existência de um sistema interestatal no qual as economias nacionais estão sob o controle de atores estatais. O sistema financeiro internacional necessita de reguladores. A partir de 
um certo ponto, reduzir o poder de intervenção do Estado provoca o aumento da exposição coletiva a riscos mais do que a expansão das possibilidades de lucro individual. Em tal contexto, a tendência em direção à integração regional aliada ao estabelecimento de mecanismos intergovernamentais de cooperação em matéria de política externa, como é o caso da União Européia, pode vir a constituir uma fonte importante de estabilidade para o ordem internacional. Não obstante dificuldades e obstáculos verdadeiros, a PESC, pelo seu caráter inovador e pioneiro em matéria de integração das políticas externas e de segurança, representa um avanço certo em direção à consolidação da estabilidade tanto econômica como política da região e do sistema internacional como um todo.

Maio de 1999

\section{Notas}

A disciplina de Relações Internacionais surgiu formalmente em 1919, quando foi criado o Departamento de Política Internacional na Universidade de Aberyswyth, no país de Galles.

Este artigo não pretende aprofundar-se na discussão teórica, mas apenas sublinhar a relevância das abordagens teóricas para o entendimento das transformações mundiais atuais. Para entender melhor as teorias de Relações Internacionais, ver, por exemplo, A.J.R. Groom e Margot Light (1994).

Ver Susan Strange (1983).

Robert Cox (1996:88).

Ver, por exemplo, Wendt (1992).

Robert Gilpin (1987:11-4).

Susan Strange (1988:18).

Susan Strange (1988:22).

Referência ao Tratado de Westfália (1648), considerado como fundador da sociedade internacional Européia. O Tratado de Westfália pôs fim à Guerra de Trinta Anos (1618-1648), durante a qual os católicos Habsburgos, que controlavam uma dinastia de Estados que compreendiam territórios do que é hoje a Áustria, a Espanha, a Itália, a Holanda, a Hungria... tentaram impor seu império sobre todas estas comunidades, algumas católicas, outras protestantes. Os Habsburgos perderam a guerra e a paz foi negociada em Westfália, levando à assinatura do Tratado de Westfália.

Ver Susan Strange (1994), capítulo 4.

Fonte: UNCTAD (1996: ix, 4).

Fred Block, seminário Instituições e Desenvolvimento Econômico. Uma Perspectiva Comparada sobre a Reforma do Estado. CPDA/NUSEG. Rio de Janeiro, 12-14 de Novembro, 1997.

Richard O’Brien (1992).

Sobre Fordismo e pós-fordismo, ver Alain Lipietz (1985).

Ver John G. Ruggie (1995).

Adaptado de Thomas Biersteker (1993).

Sobre o Consenso de Washington, ver Williamson (1990).

Cerny cita como exemplo a França e a Grã-Bretanha. Phil Cerny (1989).

É o que afirma Bresser Pereira no livro que serviu de base à definição dos rumos da reforma. Ver Luiz Carlos Bresser Pereira. Economic Crisis and State Reform in Brazil. Towards a New Interpertation of Latin America. Boulder and London: Lynne Rienner, 1996. 
A Organização Mundial do Comércio vem tratando um número crescente de casos de queixas relativas a esses temas. A questão está sendo estudada e definida por grupos de trabalho, como o Comitê sobre Comércio e Meio Ambiente, que trata do impacto dos critérios ambientais sobre a competitividade e da tentativa dos países desenvolvidos de dar uma dimensão extraterritorial a suas próprias normas.

Robert Gilpin (1987:118).

Ian Clark (1997:202).

Sobre os efeitos perversos dos choques econômicos sobre a democracia ver, por exemplo, o ensaio catastrófico de Viviane Forrester. L’Horreur Economique. Paris: Fayard, 1996.

Ver James Chace (1998:115).

Susan Strange (1988:242).

Robert Gilpin (1987), capítulo 4.

World Bank (1997).

O ingresso à União Econômica e Monetária está condicionado ao respeito dos chamados critérios de Maastricht, ou critérios de convergência, que estipulam que: a taxa de inflação não pode ser superior em mais de um ponto e meio percentual à média dos três Estados-membro com as menos elevadas taxas de inflação; o déficit público não pode ultrapassar 3\% do PIB e a dívida pública não pode ultrapassar 60\% do PIB; e, por fim, a taxa de juros de longo prazo não pode ser superior em mais de dois pontos percentuais à média dos três Estados-membro com as taxas menos elevadas.

Ver Commission of the European Communities (1992).

Susan Strange (1986).

Phil Cerny (1993:49).

Fiona Butler (1997:427).

A criação de um pacto de defesa foi um dos temas da Cúpula franco-britânica de Saint-Malo de dezembro de 1998, que resultou na assinatura de uma carta de intenções entre os dois países visando facilitar operações conjuntas entre as duas principais potências militares da União Européia.

Ver http://europa.eu.int/comm/agenda2000.

A moderna teoria do Estado distingue três formas principais de intervenção pública: redistribuição, estabilização macroeconômica e regulação. Majone sustenta que, após décadas privilegiando as funções de redistribuição e estabilização, hoje, após o reconhecimento da crise do Welfare State, a Europa se aproximou dos Estados Unidos na idéia da necessidade de privilegiar a função regulatória do Estado. Ver Majone (1994) e (1996).

Ver Marcelo de Almeida-Medeiros (1996:106) e Miriam Gomes Saraiva (1999).

Sobre o significado da União Européia para o Brasil, ver Dauster (1998).

Uma crítica séria e bem documentada à tese da "globalização forte" pode ser encontrada em Hirst e Thompson (1996).

\section{Bibliografia}

ALMEIDA, Paulo Roberto de. O Mercosul no Contexto Regional e Internacional. São Paulo: Aduaneiras, 1993.

ALMEIDA-MEDEIROS, Marcelo de. “O Mercosul e a União Européia: Uma Abordagem Comparada do Processo de Formação de Instituições”. Contexto Internacional, vol. 18, n. 1, 1996.

BIERSTEKER, Thomas. “The 'Triumph' of Liberal Economic Ideas in the Developing World”. Working Paper series on the New International Context of Development 6. Madison: University of Wisconsin, 1993.

BUTLER, Fiona. "Regionalism and Integration”. In BAYLIS, John e SMITH, Steve (eds). The Globalization of World Politics. Oxford: Oxford University Press, 1997. 
CAFRUNY, Alan. “EU Foreign Policy: From Maastricht to Amsterdam”. In CAFRUNY, Alan and PETERS, Patrick (eds.). The Union and the World: The Political Economy of a Common European Foreign Policy. The Hague: Kluwer Law International, 1998, p. 1-7.

CERNY, Phil. The Changing Architecture of the Politics: Structure, Agency, and the Future of the State. London: Sage, 1989.

. "Plulateralism: Structural Differentiation and Functional Conflict in the Post-Cold War Order". Millennium 22(1), 1993.

CHACE, James. “Bretton Woods II?”. In World Policy Journal, vol. XV, n. 1, Primavera 1998, p. 115-6.

CLARK, Ian. Globalization and Fragmentation. International Relations in the Twentieth Century. Oxford: Oxford University Press, 1997.

COMMISSION of the European Communities. "Treaty on European Union, Together with the Complete Treaty Establishing the European Community”. Official Journal of the European Communities C224, 31/8/1992.

COX, Robert (with T. Sinclair). Approaches to World Order. Cambridge: Cambridge University Press, 1996.

DAUSTER, Jorio. “União Européia: Nova Realidade e Significado para o Brasil”. In VELLOSO, João Paulo dos Reis (coord.). O Brasil e o Mundo no Limiar do Novo Século. Rio de Janeiro: José Olympio, 1998.

GILPIN, Robert. The Political Economy of International Relations. Princeton, New Jersey: Princeton University Press, 1987.

GROOM, A.J.R. e LIGHT, Margot. Contemporary International Relations: A Guide to Theory. London and New York: Pinter, 1994.

HIRST, Paul e THOMPSON, Grahame. Globalization in Question. The International Economy and the Possibilities of Governance. Cambridge: Polity Press, 1996.

LIPIETZ, Alain. Mirages et Miracles. Paris: La Découverte, 1985.

MAJONE, Giandomenico. “The Rise of the Regulatory State in Europe”. In West European Politics, 17(3), 1994, p. 78-102.

—. “A European Regulatory State?”. In RICHARDSON, Jeremy (ed.). European Union, Power and Policy-Making. London: Routledge, 1996, p. 263-277.

O’BRIEN, Richard. Global Financial Integration: The End of Geography. London: Routledge/ Royal Institute of International Affairs, 1992.

RUGGIE, John Gerard. At Home Abroad, Abroad at Home: International Liberalization and Domestic Stability in the New World Economy. Jean Monnet Chair Papers 20, Florença: European University Institute/Robert Schuman Center, 1995.

SARAIVA, Miriam Gomes. "Os processos de Integração Latino-Americanos e Europeu. As Experiências dos Anos 60 e o Modelo de Integração com Abertura Econômica dos Anos 90”. Revista Internacional de Estudos Políticos, vol. 1, n.1, 1999.

SMITH, Michael. “The EU as an International Actor”. In RICHARDSON, Jeremy (ed.). European Union, Power and Policy-Making. London: Routledge, 1996, p. 247-262.

STRANGE, Susan. “Cave! Hic Dragones: A Critique of Regime Analysis”. In KRASNER, Stephen (ed.). International Regimes. Ithaca, New York: Cornell University Press, 1983.

- Casino Capitalism. Oxford: Blackwell, 1986.

. States and Markets. London and New York: Pinter, 1988.

- The Retreat of the State. The Diffusion of Power in the World Economy. Cambridge: Cambridge University Press, 1994.

UNCTAD. Transnational Corporations and World Development. London: International Thomson Business Press, 1996.

WENDT, Alexander. “Anarchy is What States Make of It: The Social Construction of Power Politics”. International Organization, 46 (2), 1992. 
WILLIAMSON, John (ed.). Latin American Adjustment: How Much Has Happened? Washington D.C.: Institute of International Economics, 1990.

WORLD BANK. World Development Report 1997. New York: Oxford University Press, 1997.

\section{Resumo}

O artigo procura examinar a relação entre o processo de globalização econômica e a estabilidade da ordem internacional desde a perspectiva crítica da Economia Política Internacional. Sustenta-se que tal perspectiva apresenta-se como a mais adequada para pensar a questão central do debate das ciências sociais hoje: a relação entre Estados e Mercados e a tensão entre uma economia cada vez mais internacionalizada e um sistema político que permanece baseado no Estado-nação. O texto analisa as grandes transformações em curso no contexto da globalização econômica, a instauração de uma ordem política pós-Wesfálica, assim como seus efeitos sobre o papel do Estado e as relações internacionais. Em seguida, o significado da tendência em direção ao regionalismo é analisado, com o estudo do caso da União Européia e de suas novas áreas de integração política, com ênfase na Política Externa e de Segurança Comum (PESC). O artigo conclui apresentando o sucesso da União Européia como evidência da relação entre estabilidade econômica e cooperação política.

\section{Abstract}

This article examines the links between the process of economic globalization and the stability of the international order from the International Political Economy perspective. It argues that this perspective is the most appropriate to shed light on what is today the central issue in social sciences: the relation between States and Markets, and the tension between an increasingly globalized economy and a territorially-defined political system. The paper discusses the ongoing transformations in the context of economic globalization and the shift to a postWestphalian political order, as well as its effects on the role of the state and on International Relations. It then turns to the analysis of the meaning of regionalism, with the case study of the new areas of political integration within the European Union, in particular the Common Foreign and Security Policy (CFSP). The European Union provides evidence of the links between economic stability and political cooperation.

Palavras-chave: Ordem internacional. Globalização. Regionalismo. Key-words: International order. Globalization. Regionalism. 